\title{
O surfe e a moderna tradição brasileira
}

\author{
Cleber Augusto Gonçalves Dias*
}

\begin{abstract}
Resumo: O objetivo deste trabalho foi o de descrever e analisar a história do surfe no Rio de Janeiro entre as décadas de 1960 e 1970, a fim de depreender elementos de reflexão mais geral sobre o modo de desenvolvimento das suas estruturas de funcionamento. A ideia foi a de explorar as relações entre este esporte e as circunstâncias sociais mais gerais que the acompanharam e mesmo Ihe produziram. Com essa finalidade, as fontes utilizadas foram reportagens de jornais e revistas da época, tais como O Globo, Jornal do Brasil, Jornal dos Sports, Veja, Fatos e Fotos, O Cruzeiro, Brasil Surf, além de entrevistas com personagens que protagonizaram parte dos acontecimentos tratados aqui.
\end{abstract}

Palavras-chave: Surfe. Esportes. Natureza. História.

Um dos mais recentes desdobramentos nos estudos do lazer de um modo geral tem sido a análise do fenômeno dos esportes na natureza. E apesar do sensível aumento do número de trabalhos a esse respeito, tem-se ainda alguns importantes desafios teóricos que sequer começaram a ser abordados. É esse o caso, por exemplo, das suas dimensões históricas: uma faceta dessas atividades que tem apresentado grandes lacunas nas pesquisas em curso (DIAS; MELO; ALVES JUNIOR, 2007). Em verdade, há nisso um silêncio quase absoluto, onde a incompreensão histórica pode induzir a mal-entendidos conceituais ou, em alguns casos, a erros de interpretação.

A partir desse quadro, meu objetivo aqui é o de tentar apresentar algumas considerações de caráter especificamente histórico sobre uma das muitas modalidades que compõe este vasto e complexo segmento esportivo. Trata-se, mais especificamente, de uma análise histórica dos primeiros passos do processo de desenvolvimento do surfe no Rio de Janeiro; um lugar e uma modalidade que, sabidamente, tem exercido papel de considerável influência para o desdobramento de todo o campo

* Graduado em Educação Física (2004). Especialista em Educação Física escolar (2006). Mestrando em História Comparada. Pesquisador do grupo Anima (www.lazer.eefd.ufrj.br). E-mail: cag.dias@bol.com.br 
dos chamados esportes na natureza. Com essa finalidade, utilizei como fontes reportagens de jornais e revistas da época, tais como O Globo, Jornal do Brasil, Jornal dos Sports, Veja, Fatos e Fotos, O Cruzeiro, Brasil Surf, além de entrevistas com personagens que protagonizaram parte dos acontecimentos tratados aqui.

Os primeiros rumores do surfe no Brasil podem ser identificados em meados dos anos 30, quando uma dupla de jovens de Santos, no litoral paulista, fazem espontaneamente algumas iniciativas na confecção e uso das "tábuas havaianas", como eram então conhecidas as pranchas de surfe (GUTENBERG, 1989). No entanto, este foi um movimento que não repercutiu nem se irradiou e seus efeitos se encerram ali mesmo. Foi somente alguns anos depois, entre o fim dos anos 1950 e início dos anos 1960, no Rio de Janeiro, que a tal prática começaria a formar, efetivamente, um campo esportivo. Nessa época, ter-se-á os primeiros e tímidos vestígios da presença dessa prática nas praias cariocas.

Nesse ponto, deve-se destacar que não há nenhum indício de que esse desenvolvimento tenha qualquer correlação com os acontecimentos de Santos. Ou seja, não se tem nenhum tipo de vínculo ou continuidade entre esses dois eventos. Ao contrário, são dois movimentos absolutamente autônomos e que não se influenciaram em nada e em nenhuma medida - ao menos até onde se sabe. A gênese do surfe no Brasil, portanto, encontra-se no Rio de Janeiro, que foi onde a prática ganhou popularidade, gerou um mercado ao seu redor e finalmente, consolidou uma rede de atores que, dali em diante, adotariam o esporte como estilo de vida e marco formador de suas identidades.

Antes do início da década de 1960, o hábito de ficar de pé sobre as pranchas, sequer chamado surfe, ainda era um costume de lazer pouco comum, embora já tivesse seus adeptos. Esses praticantes dividiam seu tempo livre entre uma série de outras modalidades e práticas, notadamente o mergulho e a caça submarina, que ocupava lugar de destaque entre os divertimentos praianos.

De maneira lenta e paulatina, o surfe vai se apresentando como um concorrente à preferência esportiva dos jovens. A brincadeira de descer as ondas de pé sobre tábuas de madeira tomaria cada vez mais 
tempo daquela geração. A progressiva centralidade que o hábito iria ocupar pode ser percebida através da intensidade com que se dedicavam ao aperfeiçoamento das pranchas. Passado algum tempo em que se utilizavam as "portas de igreja" (um retângulo de madeira pesado, com cerca de dois metros de extensão e com bico quadrado), Irencyr Beltrão foi apresentando a um marceneiro naval que costumava fazer reparos nas embarcações dos sócios do Clube dos Marimbás, em Copacabana. Na sequência, Irencyr encomendou-lhe então a fabricação de pranchas de compensado naval, chamadas à época, “madeirites". Esse marceneiro, de nome Moacyr, conseguiu dar-lhes certa envergadura, além do bico arredondado, melhorando sua hidrodinâmica.

O aprimoramento das pranchas permite maiores facilidades no seu manuseio, tornando, de certo modo, o esporte mais atraente. Assim, o progressivo aperfeiçoamento das pranchas é um elemento importante para compreendermos a difusão desta prática, pois a partir daí, o nível de habilidade e de força exigidos serão sensivelmente menores, garantindo maiores facilidades. As "portas de igreja", por exemplo, por conta da sua baixa flutuabilidade, exigiam, antes de tudo, que as ondas estivessem consideravelmente grandes para que se pudesse deslizálas. Por si só, essa pré-condição já funciona como uma triagem, selecionando apenas os nadadores mais hábeis e mais destemidos. Também por conta da baixa flutuabilidade, era necessário o uso de nadadeiras que pudessem oferecer maior propulsão. Além de tudo, a precariedade da sua fabricação as tornava um tanto incômodas:

A ponta era virada demais e aí se entrasse na onda,
ao invés de furar por cima, freava. E a prancha era
feita com macho e fêmea, e tinha uns travessões:
você estava ajoelhado, você saía e pum, dava com o
joelho no travessão. Era bem ruim [...] Em baixo tinha
uma ripa cumprida, então, pra entrar no corte - por-
que nosso barato era cortar - tinha que entrar assim
e ir pra esquerda. E pra cortar tinha que enfiar a mão
na água, porque a tendência dela era andar reto. O
terço posterior dela era uma ripa de uns três centí-
metros de altura. Então para entrar nela era fácil: a
onda era grande, está aqui. Agora pra fazer cutbacks
era mais complicado [risos] (COLASSANTI, 2007).

Movimento, Porto Alegre, v. 15, n. 04, p. 257-286, outubro/dezembro de 2009. 
Nesse sentido, as madeirites podem ter cumprido um papel importante na divulgação do novo esporte, à medida que tornava sua prática um pouco menos exigente, e acima de tudo, um pouco menos sofrível. Todavia, as técnicas de utilização do material, e o próprio material, circulavam de forma reservada, restringindo-se a um círculo de relações muito estreito.

Nos anos que se seguiram, 1962 e 1963, dois movimentos simultâneos iriam marcar o esporte. O primeiro refere-se à ampliação das possibilidades de acesso às pranchas de madeirite. Um carpinteiro da Rua Francisco Otaviano, em Ipanema, inicia um processo de fabricação destes materiais a fim de comercializá-las. A sua disponibilização à compra, transformando-a em mercadoria destinada ao maior número possível de consumidores (já que o objetivo é auferir lucros de sua venda), amplia potencialmente o acesso ao material e permite que mais pessoas experimentassem o esporte.

Ao mesmo tempo os adeptos daquele hábito continuavam perseguindo formas de fabricar um equipamento mais adequado, sempre tendo em vista seu progressivo aprimoramento. Em 1963, Jorge Bally e Arduíno Colassanti começam a tentar fabricar pranchas de isopor. A essa altura, revistas estrangeiras (de mergulho) já traziam imagens de pranchões que eram usados na Califórnia. Foi inspirado nestes modelos que se experimentou o isopor, que logo se mostrou de difícil manipulação. Ele era derretido pelo etileno da resina de poliéster que servia como revestimento. Na busca por alternativas para isolá-lo, Colassanti descobriu na Shell uma outra resina, chamada epkot, que ao invés de poliéster, era fabricada com epox. Com este novo material conseguiu-se fazer então uma prancha de isopor, tudo de modo bastante artesanal.

As experimentações continuaram. Na praça General Osório havia uma banca de jornal que vendia revistas estrangeiras de todo tipo. Uma delas era a recém criada Surfer. Nela, já se podia ver pranchas fabricadas com fibra de vidro. Como se tratava de um material caro, outros experimentos foram ainda ensaiados.

Em suma, esses dois processos contribuíram decisivamente para a integração do surfe como um hábito mais ou menos comum e corriqueiro nas praias cariocas. De um lado, a comercialização de pranchas 
de madeirite, e de outro, a continuidade no aperfeiçoamento das pranchas (desencadeado artesanalmente pelos próprios praticantes).

Contudo, também não se deve superestimar a influência dessa última dimensão tecnológica na modulação das culturas esportivas. Outros estudos já assinalaram os problemas de análises excessivamente centradas nas inovações técnicas, num tipo de abordagem que têm apontado a necessidade de relativizá-las na compreensão da configuração de certos esportes. Olivier Hoibian (2005), por exemplo, critica compreensões sobre o desenvolvimento histórico do montanhismo que estejam moduladas pelo que o autor diz ser uma "versão muito simples e muito coerente da história da escalada". Nick Ford e David Browm (2006, p. 37) também ponderam sobre esse mesmo tipo de estrutura narrativa na história do surfe. Segundo eles, ao excessivo determinismo tecnológico, que computa mudanças no estilo e na performance dos surfistas em termos de material e formas das suas pranchas, pode ser acrescido fatores culturais mais amplos.

Concordando com essas reflexões poderíamos dizer então que existem aspetos mais gerais e de caráter propriamente mais sociológico que assumem um sentido mais estrutural e mais profundo para a modulação desses costumes no Rio de Janeiro (e consequentemente, no Brasil). Tais aspectos acabam determinando numa medida um tanto maior o rumo dos acontecimentos que se desenlaçam na sua história. Nesse sentido, o papel daqueles personagens envolvidos com a prática do surfe no Rio de Janeiro não se resumiria ao de oferecer novos materiais e em quantidade maior. Para além disso, a "patota do Arpoador" cumpriria uma função simbólica chave nesse processo de difusão do novo esporte.

Bruno Hermanny, por exemplo, um dos personagens envolvidos com o surfe àquela época, havia se sagrado bi-campeão mundial de pesca submarina, o que o colocara numa posição de destaque no mundo esportivo. Desde então, passou a ser comum referências ao seu nome em reportagens que divulgavam suas imagens, seus feitos e suas realizações. Da mesma forma, Arduíno Colassanti, que era uma espécie de ícone daquela geração, tido como símbolo de beleza e padrão de comportamento. Participou como ator das primeiras produções do Cinema Novo, sendo, inclusive, alçado ao posto de galã do movimento.

Movimento, Porto Alegre, v. 15, n. 04, p. 257-286, outubro/dezembro de 2009. 
Assim, a posição social ocupada por aquele grupo de surfistas era, em geral, privilegiada. Ainda mais se considerarmos que o momento em que o surfe ganhava espaço na agenda de lazeres da Zona Sul carioca (e mais particularmente do Arpoador), coincidia com o momento em que artistas, jornalistas e intelectuais, iniciavam a construção e divulgação de uma certa estrutura discursiva que produziria o mais novo mito carioca da ocasião: Ipanema. Dentro desse processo, os músicos da Bossa Nova, os cineastas do Cinema Novo ou um grupo de jornalistas que ficaram conhecidos como a Esquerda Festiva ganhavam destaque na cena nacional. Na esteira desse sucesso, projetavam seus costumes, isto é, os costumes de Ipanema. A este movimento mais amplo se integravam alguns personagens frequentadores da praia $\mathrm{e}$ praticantes de surfe, onde Arduíno Colassanti talvez seja o melhor exemplo. Sua participação em filmes de Nelson Pereira dos Santos, sua amizade com Roberto Menescal, com quem estudou desde a infância e que também praticava mergulho no Arpoador, seu namoro com Leila Diniz, Sônia Braga e outras musas da época, são exemplos que evidenciam as justaposições dessas redes de relacionamentos.

Tal posição desempenharia grande influência no processo de difusão do surfe. A possibilidade de ter surfistas transitando entre essas esferas, que por sua vez, eram projetadas para a cena pública da cidade e do país como portadores de um certo habitus, parece mesmo ter sido decisivo para dar visibilidade ao surfe, vinculado-o a toda essa ambiência cultural. Desse modo, foi a sua presença "no lugar certo, na hora certa e fazendo a coisa certa" que se mostrou elemento capaz de forjar o surfe como uma caixa de ressonância de todo o estilo de vida que se produzia e se divulgava a respeito de Ipanema. Nesse sentido, é interessante observar como a Bossa Nova tendeu a ser representada, tal como o surfe, como uma coisa "jovem, diurna, de frente para o mar, e esse espírito solar era o de Ipanema e do Arpoador". As suas letras, do mesmo modo, eram "uma saga oceânica: a nado, numa prancha ou num barquinho, seus compositores prestaram todas as homenagens possíveis ao mar e ao verão. Esse mar e esse verão eram os de Ipanema" (CASTRO, 1999, p. 59).

Em última análise, o surfe se tornou um elemento relativamente importante dentro do conjunto de imagens que foram utilizadas para 
a sedimentação de um jeito de ser típico daquele bairro, que, por sua vez, se projetava cada vez na cena nacional como o bairro da vanguarda artística e comportamental. O crescimento da popularidade desta modalidade, portanto, fora uma espécie de eco do aumento de prestígio que Ipanema testemunhou naquele momento. A "invenção" de um bairro que se pretendia referência comportamental para o resto da cidade (e mesmo para o país), lançando modismos e exportando tendências, criava a ambiência cultural adequada para que o modus operandi de uma determinada "patota ipanemenha", em total sinergia e integração com as demais, fosse alavancada ao estrelato. Por intermédio do processo de invenção de Ipanema, ao qual o surfe está inextricavelmente ligado, as praias do Rio de Janeiro se aprontaram para assumir os ares de uma Califórnia carioca.

Com o estabelecimento de Ipanema como centro da produção de uma nova postura diante da vida e com o fim da primeira metade da década de 1960, um ciclo de desenvolvimento do surfe se encerraria iniciando-se uma nova fase. A brincadeira improvisada daria lugar a um passatempo mais elaborado. $\mathrm{O}$ descer de pé sobre as ondas se chamaria "surf". "Portas de igreja" e "madeirites" seriam agora "pranchas". Seus adeptos seriam, primeiramente, os "pranchistas" e depois os "surfers".

Sob este aspecto, o aparecimento do surfe enquanto "surf" corresponde à incorporação de modelos de prática vindos dos Estados Unidos. Representa a integração definitiva do lazer praiano carioca à dinâmica mundial de popularização deste esporte. Equipamentos, que incluem pranchas, revistas, filmes e toda uma indumentária típica ao surfista, passariam a ser importados. Junto com os materiais vinham as concepções subjacentes a cada um deles. Pranchas de fibra de vidro com flutuabilidade muitíssimo maior do que as que eram utilizadas até então e já concebidas em tamanhos e modelos diferentes para situações específicas, ou bermudas floridas hang ti representando o culto ao hedonismo havaiano, são pequenos exemplos dessa dinâmica.

Desde o início de 1964 seria possível encontrar reportagens que atestavam essas tendências de adesão a comportamentos importados. Em janeiro daquele ano a revista O Cruzeiro dizia: "Há algo de nôvo sobre o sol do Arpoador - que, êste ano, toma feições de praias havaia-

Movimento, Porto Alegre, v. 15, n. 04, p. 257-286, outubro/dezembro de 2009. 
nas, com rapazes deslizando na crista das ondas equilibrados sôbre pranchas. E o esporte tem nome inglês: 'surfing"' (ANOVA..., 1964, p. 24). Do mesmo modo, em outubro do ano seguinte, se encontraria no Jornal do Brasil:

\begin{abstract}
nada é capaz de alegrar tanto um surfista do que um dia de ressaca em Sunset Beach, a mais famosa praia de surf, ao norte da Ilha de Oahu, no Havaí, quando as ondas chegam a 10 metros de altura (SURF..., 1965, p. 1).
\end{abstract}

Outro fator que se mostraria bastante influente é a vinda de estrangeiros. Tal como a importação de materiais, estes personagens trariam consigo uma série de convicções e modelos para o novo esporte. Nesse sentido, o nome do australiano Peter Troy costuma ser apresentado como o impulso definitivo para a sua consolidação.

O australiano aportou nas praias cariocas depois de ter participado de um campeonato internacional de surfe que se realizaria no Peru em fevereiro de 1964. Após as competições, Troy seguiu viagem pretendendo conhecer outros países da América do Sul. No Brasil, especificamente, o surfista ingressara pela Amazônia, onde acabou contraindo doenças. Foi assim, um tanto debilitado, que ele chegou ao Rio de Janeiro alguns meses depois daquele mesmo ano. Fazendo amizade na praia, conseguiu hospedar-se na casa de Irencyr Beltrão. Depois de recuperado, voltou a frequentar, como esperado, a praia. Lá, teve a chance de estreitar os laços com outros praticantes de surfe, entre os quais, Arduíno Colassanti. Este último, dono de uma prancha de isopor fabricado por ele mesmo, pôde emprestá-la a Peter Troy.

Ele pegou uma onda e "ã": ficamos boquiabertos. Ele caminhava em cima da prancha e a gente não conhecia nada disso. Fez uma ou duas manobras e na segunda onda ele deu um boton turn tão radical que arrancou o fundo da minha prancha. Eu tinha feito o fundo mais fininho porque era caro à fibra de vidro. Ele arrancou, mas eu nem me importei, só porque de ver aquelas duas manobras que ele fez: pô, é outro esporte (COLASSANTI, 2007).

Por essa época, Russel Coffin, jovem estudante do Colégio Americano e morador de Copacabana, tinha uma prancha de fibra de vidro

Movimento, Porto Alegre, v. 15, n. 04, p. 257-286, outubro/dezembro de 2009. 
fabricada nos Estados Unidos: uma Bing 9'6. De posse desta prancha, com padrão já bem superior àquelas que costumavam ser usadas na cidade, Peter Troy surfou novamente. Dessa vez, de modo que permitiu o olhar atento de muitos banhistas, dando novos usos ao material: "Aí o Peter Troy arrebentou: hang-ten e todas as loucuras que tinha direito" (COLASSANTI, 2007).

Desde então, identifica-se o início definitivo do surfe no Rio de Janeiro. Marcelo Árias (2002, p. 13), por exemplo, chega a dizer que:

Ao sair do mar, centenas de pessoas o aplaudiam! Peter tinha, mesmo sem saber, plantado a semente do verdadeiro surf em terras brasileiras. Sua performance foi tão espetacular, que muitas pessoas são unânimes em afirmar que o surf no Brasil pode ser dividido entre antes e depois da passagem de Peter Troy em nossa terra!

É certo que desse momento em diante a modalidade experimentaria crescente popularidade, ingressando, inclusive, numa nova fase do seu desenvolvimento. Mas antes de falarmos a esse respeito, observemos a questão mais detalhadamente.

Inflexões históricas não se desenrolam abruptamente. A História não dá saltos. É certo que a passagem e as "exibições" do australiano pode ter tido alguma influência, mas é difícil precisar o quanto. De todo modo, antes disso, já se tinha acesso a revistas estrangeiras, que ora mais ora menos, faziam circular novas e mais informações sobre a evolução desse esporte nos Estados Unidos. Da mesma forma, alunos do Colégio Americano, como o próprio Russel Coffin, já desfilavam com suas pranchas de fibra de vidro pelas praias cariocas. De maneira ainda mais emblemática, antes da passagem de Peter Troy, já se falava de um aumento da popularidade do esporte, bem como da admiração que banhistas sentiam pelos malabarismos de quem ficava de pé sobre pranchas. Em janeiro de 1964, portanto antes da passagem de Peter Troy pelo Brasil, a revista O Cruzeiro (A NOVA..., 1964, p. 92) dava notícia de "NOVE 'pranchistas' que enfeitiçavam os frequentadores das praias cariocas com seus malabarismos sôbre as ondas [...] Em suas pranchas de 2,5 m êles dominam com graça e arrôjo, as ondas do Arpoador." Com relação aos praticantes, diz-se que:

Movimento, Porto Alegre, v. 15, n. 04, p. 257-286, outubro/dezembro de 2009. 


\begin{abstract}
Desde há muito os cariocas do Pôsto 6 e Arpoador invejavam os praticantes do "surfing" das praias havaianas. Faz dois anos que os pioneiros dêste emocionante esporte, no Brasil, resolveram aproveitar as ondas do Arpoador, para conseguir a chamada "Emoção dos Deuses". A prática difundiu-se aos poucos entre os habitués das praias, e formou-se um grupo de apaixonados.
\end{abstract}

A reportagem de 1964 já faz alusão a um período pregresso de dois anos. E, quando por falta de ondas adequadas, os "pranchistas" se deslocam para outras praias, como as da Barra da Tijuca e do Recreio dos Bandeirantes, os moradores da Zona Sul ficavam "privados de um espetáculo bonito, a que já estavam acostumados" (ANOVA..., 1964, p. 93). Falando de "acrobacias", "peripécias" ou do "absoluto domínio dos movimentos" que faziam da prática "um esporte fascinante", a revista atestava que "Atualmente, êste esporte atingiu enorme popularidade. - Os fabricantes de pranchas só aceitam encomenda com duas semanas de antecedência. Elas custam cêrca de Cr\$20.000,00" (A NOVA..., 1964).

Na mesma reportagem, já se falava que Múcio, um dos nove "pranchistas", se preparava para as competições do Peru (a mesma que Peter Troy participaria). Portanto, vai se evidenciando que antes mesmo da vinda do australiano ao Brasil um processo de difusão e institucionalização do surfe, mais ou menos sob os moldes em que era praticado nos Estados Unidos, já estava deflagrado. Fala-se, inclusive, de um campeonato que teria acontecido meses antes no Arpoador.

Por tudo, é difícil imaginar que em alguns poucos meses criou-se a disposição necessária para organizar uma federação, uma competição ou toda uma disponibilidade para iniciativas nesse sentido. Ainda mais uma disposição despertada apenas pela passagem de um único homem através de uma ou duas exibições. Em suma, a influência de Peter Troy para o surfe no Rio de Janeiro teve sua importância, mas uma importância mais relativa do que se costuma dizer. Parece ser mais produtivo considerar que os acontecimentos que seguiram ao longo do ano de 1964 se referiam a um processo que já estava deflagrado antes da passagem do australiano, sendo esta apenas sua culminância. $\mathrm{O}$ culto dogmático à este personagem parece muito mais

Movimento, Porto Alegre, v. 15, n. 04, p. 257-286, outubro/dezembro de 2009. 
uma reprodução cega dos paradigmas historiográficos que superdimensionam a ação de indivíduos isolados, em detrimento do acúmulo de experiências cotidianas, um tipo de historiografia que, no limite, mitifica determinadas ações e certos personagens, tornando-os heróis e desconsiderando que o desenvolvimento de uma prática social, tal como o surfe, é o resultado produzido por uma cadeia interdependente de fatores, que incluem uma ampla rede de atores, disputas, conflitos e realizações.

Uma das teias fundamentais dessa rede diz respeito à consolidação de uma geração identificada especificamente ao surfe. Nesse sentido, importa sublinhar, a despeito dessas polêmicas que, dali em diante, apareceria um grupo de jovens que se apresentavam publicamente como surfistas. Agora, já não se tratava de um grupo de jovens adeptos de várias modalidades de praia, entre as quais, o surfe. Este deixava de ser "mais uma opção" e ia se configurando para alguns como "a opção". Cristalizava-se uma geração cujas identidades se edificariam já em função do surfe, direta e especificamente.

Em abril de 1966, por ocasião da realização de um campeonato no Arpoador, dizia-se: "uma perfeita distinção já está sendo feita em Ipanema (e isto foi comprovado no campeonato do Arpoador): o aparecimento da Geração Surf, inteiramente diferente da Geração Iê-Iê" (KERR, 1966, p. 18).

As características atribuídas à “Geração Surf” diziam respeito à exibição de um certo "estilo", que incluía shorts e camisas com desenhos e cores vinculadas ao universo do surfe. Ao lado desses caracteres, tem-se a espontaneidade e a descontração - maior do que em qualquer outra geração.

\footnotetext{
A moda surf foi praticamente lançada em grande estilo no concurso de fim de semana. Tanto as môças como os rapazes exibiam um conjunto de côres, que agora fazem parte do surf. Para o verão que vem os calções surfe as camisas com letreiros e desenhos de onda já estão garantidos [...] As meninas da Geração Surf foram um sucesso absoluto. Coloridas e mais descontraídas que qualquer outra geração - as meninas surf estavam em tôdas (KERR, 1966).
}

Movimento, Porto Alegre, v. 15, n. 04, p. 257-286, outubro/dezembro de 2009. 
A aparição de determinados hábitos alimentares também é um exemplo bastante esclarecedor do processo de construção de símbolos específicos desta identificação. Nessa mesma época foi inaugurada a lanchonete "Balada", situada à época entre a rua Teixeira de Melo e a praça General Osório, em Ipanema. A lanchonete, que se dedicava especificamente à venda de sucos, acabou atraindo os surfistas que adotaram o consumo de alimentos naturais como uma alternativa. Com o tempo, tais hábitos se espalharam pela cidade e a exemplo de outros simbolismos deste esporte, mas que também se faziam presente em outras esferas de atuação, acabou influenciando a cidade como um todo. Isto é, sem terem sido necessariamente inventados pelos surfistas, o envolvimento deste grupo com tais hábitos atribui-lhes certos significados que diziam respeito ao próprio surfe, conferindo-lhe assim, características análogas. Dessa forma, consumir sanduíches e sucos naturais foi se transformando em sinônimo de autenticidade e inovação nos costumes, algo ligado a pessoas que, tal como os surfistas, prezavam a possibilidade de irmanar-se com a natureza.

No fim, todo este quadro acabou aprofundando a disposição para se buscar no exterior um quadro de referências morais e materiais para o esporte (e consequentemente para a cidade). Equipamentos, roupas e concepções esportivas associadas ao seu desenvolvimento nos Estados Unidos passaram a ser deliberadamente trazidos ao Brasil. Se antes tais influências eram quase circunstanciais, acessadas ocasionalmente através de alguma revista ou de algum filme, agora, eram mais constantes e intencionais. Havia já um conjunto de atores que as desejavam e as buscavam. Pranchas de fibra de vidro passaram a ser importadas sob um valor que variava de 100 a 200 dólares. Além disso, os primeiros brasileiros começam a viajar para o Havaí. ${ }^{1}$

Assim inicia-se o culto ao surfe como uma atividade que exige grande dedicação, que deve ser "levada a sério", como um estilo de

\footnotetext{
${ }^{1}$ O primeiro nome de que se tem notícia é o de Carlos Eduardo Soares, o Penho, que viajou ao Havaí em 1966. Lá participou de campeonatos e conheceu nomes consagrados do esporte. No seu regresso, trouxe na bagagem as "minimodels", pranchas muito menores do as que se usavam, e que entre outras coisas, permitia maior mobilidade ao surfista (KAMPION, BROWN, 2003; MARCUS, 2007; YOUNG, 1994). Trouxera também novas técnicas e materiais de fabricação, sem mencionar outros hábitos como os de viajar, a vida simples e assim por diante.
}

Movimento, Porto Alegre, v. 15, n. 04, p. 257-286, outubro/dezembro de 2009. 
vida e uma filosofia. Na expectativa de realizar os objetivos dessa experiência existencial um grupo elege Saquarema como "lugar sagrado de peregrinação" (SAQUÁ..., 1975, p. 36). Bem nos moldes dos primeiros californianos que "descobriam o Havaí", esses surfistas se caracterizavam pelo desejo de viajar, pelo desprendimento de posses materiais e por uma vida simples, "dormida sob a luz do luar".

Outra prova da intensificação do papel desempenhado pelas referências estrangeiras é o de Guilhermão, um jogador de futebol de areia, surfista e "naturalista por natureza" que, já nos meados dos anos 70, inaugurou na Barra da Tijuca o primeiro restaurante vegetariano integralmente natural.

Guilhermão pretende introduzir um costume de muitos surfistas havaianos e californianos que preferem comer mais qualidade substancial em menos quantidade, ao invés de rangos sintéticos (TOQUES..., 1975, p. 43).

No mesmo sentido, em junho de 1965 iniciou-se um esforço para a criação da Federação Carioca de Surf. A iniciativa se mostraria importante, e não só por organizar campeonatos, mas também por fazê-lo com a presença de alguns surfistas americanos, o que alavancaria ainda mais a promoção do esporte. Em março de 1966, por exemplo, Mark Martinson e Dale Stuble estiveram presentes em competições realizadas no Arpoador. Contando com a presença de mais de 60 surfistas, a competição, que teve apoio da revista Fatos e Fotos, também parece ter tido um considerável número de espectadores

O mar muito calmo, sem ondas fortes, prejudicou o
que poderia ser uma grande exibição dos craques
americanos, mas não chegou a diminuir o êxito da
prova, que foi acompanhada por um grande público
(KERR, 1966).

Curioso é que, nesta competição, do total de 60 participantes, "a maior afluência ocorreu na classe dos juniores". Com suas preferências pelo uso das pranchas importadas de fibra de vidro, "estão atingindo um ótimo aproveitamento". (KERR, 1966).

Oito meses depois, no final de novembro, a Federação organizaria outra competição. Esta, contou com o apoio da Coca-Cola e do Gover-

Movimento, Porto Alegre, v. 15, n. 04, p. 257-286, outubro/dezembro de 2009. 
no da Guanabara. A entrega da premiação pôde contar, inclusive, com a presença do governador. Sem maiores precisões, fala-se também de grande número de aficionados:

\begin{abstract}
Apesar do mar bastante calmo, com ondas relativamente baixas, a não ser quando em algumas 'séries', o carioca de surf foi coroado de êxito. O tempo estava em boas condições e foi grande a afluência de banhistas a praia do Arpoador, que assistiram o desenrolar da competição tomando banho de sol (SURF..., 1966, p. 14).
\end{abstract}

Esse conjunto de acontecimentos vai evidenciando um aumento do interesse pelo esporte. Na cobertura deste primeiro campeonato realizado pela federação já se dizia que "em poucos meses, o surf provou que se fixará entre nós, pois é um esporte bem atraente" (FERNANDA..., 1965, p. 6). Pouco a pouco a organização desses eventos parece ter facilitado o desabrochar de mais curiosidades a respeito do novo costume. "O público ainda não está acostumado com o surf, mas já há os que vão aos dirigentes e fazem perguntas de como é feito o julgamento" (FERNANDA..., 1965).

Desse modo, deve-se mesmo destacar o papel que a Federação Carioca de Surf desempenhou naquele contexto. A iniciativa, que se resumira a um empreendimento extraoficial, já que o Conselho Nacional de Desporto não chegou a autorizar sua efetiva criação, organizou, assim mesmo, competições com a presença de surfistas prestigiados no exterior e que contavam com apoio e patrocínio, sem mencionar a cobertura dos meios de comunicação que ajudavam a divulgar o novo esporte.

Nesse período também começam a surgir as primeiras iniciativas comerciais “mais sérias". Em 1965 um coronel da aeronáutica chamado José Freire Parreiras Horta abriria uma fábrica de pranchas: a São Conrado Surfboards. Pouco tempo depois, em 1969, o coronel Parreira, como era conhecido, compraria licença para fabricar pranchas de poliuretano, importadas ao Brasil pela empresa Clark Foam, cujo representante nacional era Russel Coffin, o mesmo que emprestou sua prancha para Peter Troy em 1964. No mesmo sentido, cita-se o aparecimento da primeira loja especializada na venda de acessórios e roupas ligadas ao surfe: a loja Magno. Além de importar roupas, a loja

Movimento, Porto Alegre, v. 15, n. 04, p. 257-286, outubro/dezembro de 2009. 
oferecia premiação nas competições (em 1966, organizaria seu próprio campeonato: o Campeonato de Surf da Magno). Logo em seguida, inaugurou-se mais duas lojas, a "Ala Moana" e a Ocean Pacific (OP), de propriedade do Cidão. Este último, segundo Rico de Souza, que esteve diretamente envolvido com o surfe nessa época,

foi um dos primeiros a encarar o surf no Brasil com
uma visão empresarial. Ele começou com lojas de
varejo e depois partiu para a indústria, com confecção
própria [...] Em 1976 Cidão levou o surf para a re-
gião sul do país, promovendo competições em Floria-
nópolis, Santa Catarina (SOUZA, 2007).

Nessa época, desenvolve-se também uma forte relação do surfe com a ambiência contracultural daqueles tempos. De um certo modo, os surfistas passaram a ser um dos grupos que encarnavam os ideais hippies. A realização desses ideais só era possível, em larga medida, graças a estrutura familiar desses jovens, cuja condição econômica garantia-lhes a possibilidade de uma vida dedicada a fazer nada; preocupados em não se preocupar (VELHO, 1998, especialmente cap. 4). Mas é óbvio que a realização do sonho do verão sem fim não seria sustentado pelas famílias ad infinitum. Cedo ou tarde as "maravilhosas crianças do underground carioca" - como a imprensa costumava chamálos - teriam que crescer e garantir seu sustento com recursos próprios.

Um caminho possível para conjugar a vida nômade do surfe com as necessidades de emancipação da maioridade era profissionalizá-lo, isto é, garantir meios de se extrair do próprio divertimento formas de subsistência. Nesse sentido, amplia-se um movimento de tentar organizar o esporte em termos comerciais. Na prática, isto se traduz num esforço de lhe garantir uma organização institucional capaz de promovêlo nos moldes esportivos convencionais, qual seja, com premiações, patrocínios, campeonatos e rankings. Valendo-se de uma racionalidade empresarial, que ganhava cada vez mais espaço nas mentalidades brasileiras de um modo geral, o surfe se integraria às dinâmicas macrossociais de ampla comercialização de bens simbólicos que marcaria os anos 70 .

No surfe em particular, desde o início dos anos 60 vê-se um dilema que até os dias de hoje divide opiniões. Trata-se da cisão entre um grupo partidário da profissionalização do esporte e um outro, partidário do

Movimento, Porto Alegre, v. 15, n. 04, p. 257-286, outubro/dezembro de 2009. 
surfe como um "estado de espírito". Os primeiros defendem o incremento de organizações institucionais e da quantidade de competições, que devem contar com prêmios em dinheiro e toda a estrutura típica do espetáculo esportivo. Os segundos, veem nessas iniciativas uma distorção dos verdadeiros sentidos do esporte (BOTH, 1995).

As diferenças quanto essas formas de conceber o esporte produziram uma verdadeira cisão. Na Califórnia, por exemplo, Mickey Dora passou a combater ferrenhamente a popularização do hábito de surfar, em larga medida proporcionado pela massiva distribuição das imagens do esporte através de filmes e produtos, que realmente iam atraindo uma multidão para as praias. O crescente número de praticantes causava o descontentamento de alguns, tais como o próprio Dora, que acusavam tal processo como sendo o responsável pelo incômodo aumento do número de surfistas.

No Brasil, polêmicas envolvendo posições contrárias ou partidárias à comercialização e institucionalização do surfe não replicaram, nessa época, com a mesma intensidade. Provavelmente porque nos anos 60 ainda não havia um público consumidor de surfe em número tão considerável assim e, por conseguinte, os mecanismos de comercialização não seriam tão ostensivos. Ao mesmo tempo, o próprio processo de industrialização da cultura de uma forma mais geral ainda era bastante precário entre nós. Cinema, rádio, televisão, imprensa, teatro, música, tudo era comercializado de modo bastante artesanal e improvisado, não conseguindo criar uma cadeia produtiva com alcance suficientemente abrangente. Os primeiros passos de comercialização do surfe não fugiram a regra.

No entanto, com o golpe civil-militar de 64 , a continuidade e mesmo o aprofundamento no desenvolvimento de padrão de produção e sociabilidade de tipo capitalista estariam assegurados. O novo regime permitiu a ampliação dos recursos materiais para a industrialização da cultura, bem como, através de suas políticas econômicas, o fortalecimento das classes médias, aumentando assim o número de consumidores possíveis. As consequências de tais dinâmicas para o campo esportivo, e particularmente para o surfe, se fariam notar nos anos 70 . Nessa época já se tem uma massa de consumidores disponíveis para a aquisição de produtos relacionados ao novo esporte, já devidamente

Novimento, Porto Alegre, v. 15, n. 04, p. 257-286, outubro/dezembro de 2009. 
estabelecidos como uma cultura e um novo estilo de vida. No editorial da revista Brasil Surf de novembro/dezembro de 1975, pode-se ler:

Cada vez mais, pode-se notar a presença de surf, surfistas ou correlatos em revistas, jornais e televisão. Este fato pode ser parcialmente explicado porque, quase que de uma hora para outra, uma "explosão surfográfica" fez com que invadisse as casas deixando atônita uma geração que não conseguia entender bem o que estava acontecendo. De repente viram seus filhos com uma maneira diferente e característica de falar, se vestir e até de pensar. Além desses próprios surfistas, que procuram ter acesso a todo tipo de informação que lhes diga respeito, essa geração surpresa se constitui num excelente mercado para estes jornais, revistas e televisão (EDITORIAL, 1975a, p. 7).

A disposição desses consumidores está ligada tanto a disponibilidade financeira para a compra de materiais, quanto à disponibilidade moral para a recepção e aquisição desses produtos e de todos os valores que eles encerram. Da mesma forma, já se tem também um aparato técnico mais elaborado que permite a produção de acessórios e equipamentos mais sofisticados e em quantidade maior. Por último, pode-se citar ainda a sedimentação de uma mentalidade mais gerencial entre os próprios praticantes, que além de precisarem de receitas para sua emancipação econômica, vão se embebedando nessa nova sensibilidade industrial-comercial que assola o país em vários segmentos, incluindo o esportivo.

Já em 1973, Maraca, um surfista que havia abandonado o curso de administração de empresas da PUC para "viver do esporte" já dizia que o surfe estava mudando.

Imagine que veio aqui um cara do programa "Flávio Cavalcanti" propor para a gente agitar a Vera Fischer como "Miss Surf". É um troço ridículo, mas, se pintar alguma grana, a gente vai ter que topar [...] Eu me toquei a tempo. Rompi com as engrenagens e hoje vivo do surf. Mas, pô, não é fácil, podes crer. Faço prancha para vender, mas já fui obrigado a vender até a minha prancha para descolar o leite da criança (SURFE..., 1975, p. 75).

Movimento, Porto Alegre, v. 15, n. 04, p. 257-286, outubro/dezembro de 2009. 
Em princípio, a transformação do surfe em algo comercializável sofria de certo paroxismo, sem que isso chegasse a ser percebido propriamente como um dilema. Na prática, isto significava a abertura à possibilidade de fabricar e vender materiais, numa atitude que se queria "alternativa" e "contrária ao sistema". Ao mesmo tempo, iniciativas de exploração comercial mais abrangentes e com alcance maior eram avaliadas como ridículas, mas possíveis, caso envolvessem dinheiro.

O limite entre essas duas opções, estabelecido de maneira bastante intuitiva e esotérica, parece ser a "cultura da subsistência", ou seja, enquanto se comercializa em pequena escala, para o próprio sustento, isto não representa uma distorção de valores. A partir do momento em que se tem a produção de excedentes, o lucro excessivo ou a "mais valia", então o processo estaria sujeito a críticas.

De maneira mais geral, poderíamos dizer - parafraseando David Both (1995) - que existe uma ambiguidade no prazer e na disciplina. A institucionalização do esporte, que significa sua modulação nos termos do espetáculo esportivo, encerra algum nível de disciplinarização. É preciso determinar antecipadamente, por exemplo, um calendário para as competições e nem sempre o local das disputas serão os que tem as melhores ondas ou nem sempre serão o da preferência dos surfistas. O processo pode trazer, portanto, algum nível de descontentamento, forçando os surfistas a contrariarem suas predileções. Terse-á ainda, inevitavelmente, alguns outros embaraços, tais como a necessidade de treino, o cumprimento de contratos e uma série de outras responsabilidades. Nesses termos, o conteúdo libertário, transgressor e transcendental fornecido pela experiência do contato com o mar, que, de acordo com muitos surfistas, "denota uma vivência quase espiritual", seria substituído por uma mentalidade mais convencional, isto é, mais condizente com a competição e com a busca de lucros e resultados. O esporte seria então profanado.

Por outro lado, e paradoxalmente, essas serão as circunstâncias que produzirão as condições necessárias para a concretização de uma vida que se realiza no surfe. Ou seja, para o surfista, ter um aparato institucional à disposição significa a possibilidade de ter patrocinadores que lhe permitirão ser surfista vinte e quatro horas por dia, reali-

Movimento, Porto Alegre, v. 15, n. 04, p. 257-286, outubro/dezembro de 2009. 
zando todos os seus ideais. Shaun Thomson, famoso surfista dos anos 70, exprime bem esse sentimentos numa entrevista concedida a Rico de Souza. Quando perguntado sobre o que pensava a respeito dos campeonatos e do surfe profissional ele resumira a situação dizendo: "o profissionalismo é, indiscutivelmente, a melhor maneira de unir o útil ao agradável. Dinheiro para pegar onda" (SHAUN..., 1975, p. 33).

Alguns outros casos são emblemáticos dessa ambiguidade. Mickey Dora, a quem já fiz referência, tornou-se famoso no mundo do surfe, não só por seu estilo, mas também por ser um dos principais difusores de um discurso de ódio contra a comercialização do esporte. Em artigos escritos na revista The Surfer, criticou frontalmente iniciativas como o filme Gidget, que segundo ele, convertia uma horda de garotos em novos surfistas que invadiam a praia de Malibu. Logo ele que, curiosamente, não só contribui para o roteiro do filme como trabalhou de dublê nas cenas de praia. O tom hostil e agressivo das suas ideias também não lhe impediu de fabricar seu próprio modelo de prancha para comercialização, tampouco de ser garoto propaganda das marcas Hang Ten e Greg Noll, aparecendo em anúncios de página inteira de revistas especializadas (D’OREY, 2006, p. 14).

No Brasil, o discurso e as práticas de alguns surfistas também expressavam tais contradições. O já mencionado Maraca é um exemplo interessante nesse sentido. Além dele, outros praticantes se arriscavam em pequenos empreendimentos, sobretudo os de fabricação e venda de pranchas. A frequência cada vez mais constante às paisagens internacionais, sobretudo os Estados Unidos, pode ter contribuído nesse processo, pois assim os brasileiros se colocavam em contato direto com os últimos movimentos de esportivização do surfe, participando de campeonatos organizados por uma associação profissional e testemunhando in loco o crescimento da sua indústria.

Fernando Mendonça Lima, o Fedoca, quando comentando as tendências de profissionalização do surfe, cita essas dinâmicas. Segundo ele:

A rapaziada viajou, se deu bem lá fora, trouxe ideias novas, nome, experiência, que influiu decididamente, amadurecendo o surf nacional [...] O contato com o surf internacional mostrou ao surfista brasileiro a

Movimento, Porto Alegre, v. 15, n. 04, p. 257-286, outubro/dezembro de 2009. 
possibilidade de se conseguir uma remuneração pela qualidade do surf que pratica (FEDOCA..., 1975, p.38).

Tudo isto pode mesmo ter influenciado as expectativas deste segmento no Brasil, que passariam a desejar a inserção do esporte brasileiro nessas últimas tendências. Não por acaso, é exatamente depois do início das viagens que se inicia uma febril multiplicação de fábricas de pranchas, bem ao estilo soul garage californiano. O surfe brasileiro saía da era dos "pranchões importados" e ingressava na fase das pranchas e pranchinhas de fabricação nacional.

Em 1972, tem início o primeiro "Festival de Surf de Ubatuba", competição que reuniria surfistas de todo o Brasil (especialmente do Rio de Janeiro e de São Paulo, onde a prática também já se encontrava difundida). Iniciativa de Paulo Jolly Issa, que no ano anterior havia fundado a Associação de Surf de Ubatuba, a competição é um indício importante do crescimento de uma mentalidade de esportivização. Já na sua segunda edição, no ano seguinte, que reuniu aproximadamente mil pessoas (entre público e competidores), reivindicava-se que a Confederação Nacional de Desportos (CND) reconhecesse a prática do surfe como um esporte e não como um mero passatempo (SURFE..., 1973, p. 61).

Mais ou menos no mesmo sentido, em 1975, a loja Magno inovaria uma vez mais, iniciando a fase do incentivo aos atletas. Naquele ano, um grupo de seis surfistas carioca foi à competição do litoral paulista como a "equipe Magno", tendo a loja fornecido transporte, uniforme, alimentação e hospedagem. ${ }^{2}$ A presença da equipe foi marcante $\mathrm{e}$ chamou muita atenção.

Com toda a assistência possível e todos os detalhes previamente preparados [...] a Equipe Magno, composta por seis dos melhores surfistas do momento, formou um excelente time, o que vem demonstrar que o ‘surfista brasileiro' já começa a encarar o surf profissional de maneira diferente (UBATUBA, 1975, p. 14).

2 São eles: Paulette, Kadinho, Ricardo Bocão, Marquinho Boronguer, Paulo Proença e Otávio Pacheco.

Movimento, Porto Alegre, v. 15, n. 04, p. 257-286, outubro/dezembro de 2009. 
Na mesma época, a loja chegaria até mesmo a financiar viagens internacionais para alguns surfistas, como o fizera com Rico de Souza, e, na sequência, organizar competições, como o fora o Campeonato Magno no Arpoador.

No mesmo ano (1975) acontecia o primeiro Festival de Surf de Saquarema, que aconteceria com frequência anual até 1983 (com exceção de 1979 e 1980). Durante estes eventos, a "onda de reconhecimento do surfe enquanto um esporte" se tornaria cada vez mais ostensiva. Falava-se de forma crescente da necessidade de elevar o status de seus praticantes de "feras", como eram chamados até então, para "atletas amadores". Quando da realização do Festival de 77 , já se dizia que:

cultivado em níveis de competição, o surfe brasileiro já não é apenas uma desorganizada atividade de lazer. Os torneiros são disputados com regras definidas e a vitória, como em qualquer outro esporte, depende principalmente de treino e experiência (SURFE..., 1977, p. 91).

No entanto, o estabelecimento de equivalências entre o surfe e "qualquer outro esporte" não era tão fácil. Esse empreendimento esbarraria na barreira moral colocada pela "ambiguidade do prazer e da disciplina", que fazia com que muitos surfistas se mostrassem arredios a tais mudanças. Assim, a principal e mais séria dificuldade para reconhecê-lo como esporte seria encontrar esportistas dispostos a tal.

Colocados ante a expectativa de abandonar a liberdade e relativa anarquia com que vêm se dedicando à sua prática, muitos surfistas reagem à perspectiva de se transformarem em cartolas com a irreverência de Ricardo Lima, o Ricardo "Bocão", de 19 anos, um dos favoritos do IV Festival: "Esse negócio de burocracia não é comigo. Meu negócio é tirar onda, bicho, não sentar atrás de mesa" (SURFE..., 1977, p. 91)

Na ocasião, Ricardo Bocão ainda não sabia que anos depois ele se tornaria um empresário bem sucedido do mundo surfe, sócio proprietário do canal esportivo Woohoo, colunista da revista Fluir, além de outras iniciativas empresariais. Assim, ao mesmo tempo em que os Festivais de Saquarema evidenciavam o impulso inequívoco rumo a

Movimento, Porto Alegre, v. 15, n. 04, p. 257-286, outubro/dezembro de 2009. 
esportivização, eles também seriam o lugar onde todas as contradições e ambiguidades colocadas pelos dilemas do prazer ou da disciplina se manifestariam, talvez de forma ainda mais aguda. Produto de uma época onde a "mentalidade do crescimento do esporte" já se encontrava mais amadurecida, os Festivais de Saquarema ampliaram o grau de atratividade a grandes empresas patrocinadoras. Já na primeira edição do evento, que teve 120 surfistas convidados, contou-se com a promoção da "Ala Moana Surf Shop", da "Rio Tur" e da "TV Rio", além do patrocínio da companhia aérea "Pan Am" (CAMPEONATO..., 1975, p. 28).

Do mesmo modo, nos Festivais de Saquarema foram se apresentando um grupo de surfistas que, nos anos seguintes, seriam os primeiros atletas propriamente ditos, um grupo que passaria a se dedicar ao surfe já tendo em vista certas performances nas competições como é o caso de Pedro Paulo Lopes, o Pepê, que venceu o Festival de 76, obteve, no mesmo ano, a sexta colocação no Pipeline Master (um prestigioso campeonato disputado no Havaí) e, no fim da década, se tornaria ainda campeão mundial de asa delta, marcando o início da geração dos "atletas da natureza", uma "geração de saudáveis atletas campeões [que] perseguem o brilho do sol com pranchas, velas e asas deltas" (OS ATLETAS..., 1982, p. 54).

Por outro lado, as influências comportamentais (e contraculturais) que grassavam sobre o esporte também se manifestavam intensamente e eram avaliadas como empecilhos. A conduta de muitos surfistas ou simpatizantes, pautada na experimentação de drogas e no sexo livre, repercutia negativamente na cobertura da imprensa, criando, supostamente, uma imagem contraprodutiva para o esporte. Esportivizá-lo nesse caso, significava moralizá-lo, isto é, associá-lo a imagens de saúde e bem estar físico.

A forma como os Festivais de Saquarema eram retratados representavam o oposto disso. "Parece ter havido a intenção de dar ao que estava programado um caráter dos festivais do fim dos anos 60 " (SAQUAREMA..., 1976, p. 19) e "até os jornaizinhos de bairro publicavam manchetes difamatórias do tipo 'A verdade sobre o Festival de Surf” (SILVEIRA, 1977, p. 7). Confusões de toda ordem e prisões

Movimento, Porto Alegre, v. 15, n. 04, p. 257-286, outubro/dezembro de 2009. 
eram a tônica do evento que, além das competições de surfe, contava também com um festival de música. Os eventos seguintes chegaram a ter um clima de "insegurança e incerteza quanto à sua realização" (SAQUAREMA..., 1977, p. 11). Ainda assim, e talvez por isso, os primeiros festivais obtiveram sucesso em termos de repercussão. Sua imagem porém estava longe daquela desejável para torná-lo respeitável. Ao menos era o que pensava muitos dos envolvidos.

Contrapondo-se a essas imagens, buscava-se fortalecer a ideia do surfista como alguém que "dava duro no dia-a-dia, trabalhando na manufatura de pranchas, acessórios e vestimentas" (ÁRIAS, 2002, p. 8). Nesse sentido, a criação de uma revista especializada, escrita, editada e produzida por agentes autóctones, apresentava-se como uma possibilidade de inversão dessas representações. Acreditava-se que se retratado pelos próprios surfistas, o esporte não seria tão estereotipado. Por iniciativa de Alberto Pecegueiro e Flávio Dias, em 1975 lança-se a "Brasil Surf", primeira revista especializada neste esporte no país, e que, entre outras, tem nos servido de fonte até aqui. Seus objetivos e propósitos eram claros: divulgar o esporte no país, torná-lo estável, adulto e digno, bem como formar uma nova consciência voltada para o futuro do esporte no Brasil. Logo no editorial do primeiro número se lê:

Nosso propósito é divulgar o surf e o surfista brasi-
leiro [...] BRASIL SURF pode ser o primeiro passo
concreto para a tão almejada união dos surfistas bra-
sileiros. União que se faz necessária. Já é tempo deste
esporte se tornar estável, adulto, digno da força que
conseguiu entre seus inúmeros adeptos. Número que
aumenta a cada dia e que precisa ser mais ainda incre-
mentada. É por isso que surgiu essa revista. BRASIL
SURF tem um objetivo prioritário: formar uma nova
conscientização, voltada para o futuro do surf no Bra-
sil (EDITORIAL, 1975b, p. 5).

No editorial do terceiro número, fala-se da repercussão e da receptividade que o meio surfístico teve para com a revista, o que se media, em parte, pela curiosidade na aquisição do primeiro número e na resposta da publicidade. Sua tiragem que se iniciou com 6.000 exemplares na primeira edição fora aumentada para 20.000 na quarta. Se-

Movimento, Porto Alegre, v. 15, n. 04, p. 257-286, outubro/dezembro de 2009. 
gundo os editores: "O primeiro número praticamente se esgotou em uma semana o que nos forçou a imprimir uma segunda edição, já que a primeira não chegou a sair do Rio de Janeiro, ou melhor, da Zona Sul" (EDITORIAL, 1975c, p. 9).

Com isso quer-se destacar a ideia de uma "maturidade profissional" no surfe brasileiro. Pouco a pouco surge o entendimento de que um mercado se consolida em definitivo no Brasil, o que traz certa estabilidade para futuras iniciativas de investimento. O mercado, que a princípio não parecia tão grande, surpreende. Esta surpresa, por sua vez, traz segurança e fortalece a convicção quanto à necessidade de incrementar-se o número de praticantes através de outras iniciativas. É emblemático sobre este aspecto que, em 1976, no mesmo ano em que o jornal O Globo oferece ampla cobertura ao Festival de Saquarema e repentinamente passa o surfe das páginas policiais para a de esportes, Alberto Pecegueiro e Flávio Dias, idealizadores da Brasil Surf, tenham, um ano depois da criação da revista, se articulado com Livio Bruni Júnior e Nelson Machado, proprietários da loja "Waimea Surf Shop", para a realização de uma grande competição internacional. A disputa, que de fato se realizou anualmente entre 1976 e 1982, seria, nas palavras de Marcelo Arias (2002), o "terceiro membro da trilogia sagrada dos campeonatos de surf dessa época" (ao lado dos de Ubatuba e dos de Saquarema).

O "Waimea 5000", como foi batizado o evento, ofereceu cinco mil dólares em prêmios e atraiu um público espectador de dez mil pessoas. Para sua realização, seus promotores se empenharam em convencer os membros da International Professional Surfers (IPS) da viabilidade financeira do surfe brasileiro. A ideia de organização de grandes eventos internacionais - que estava de acordo com aquele sentimento de surpresa desencadeado pela receptividade dos consumidores diante da oferta de certos produtos, tais como a própria revista Brasil Surf - ganhou fôlego.

Usando o argumento de que o Rio de Janeiro era, além de tudo, parada quase obrigatória para quem saísse da África do Sul em direção aos Estados Unidos, conseguiu-se, finalmente, fazer do "Waimea 5000" um grande e importante campeonato internacional.

Movimento, Porto Alegre, v. 15, n. 04, p. 257-286, outubro/dezembro de 2009. 
A partir de então, o que se seguiu foi uma série de megaeventos que impulsionaram verdadeiramente o surf nacional, uma vez que o público sempre foi gigantesco, e isso atraía o interesse de inúmeros patrocinadores, tais com a US top, a CCE, a Volkswagen, entre outros (ÁRIAS, 2002).

A essa altura a TV Globo já patrocinava Rico de Souza e a cervejaria Brahma fazia o mesmo com Daniel Fredman.

Encerrava-se assim o início do surfe no Rio de Janeiro. Daí em diante, o esporte estaria definitivamente, e cada vez mais integrado a paisagem da cidade. Sua participação na cena carioca de esporte e de lazer seria crescente. Ao longo da década de 80 surgiriam moradores de favelas e mesmo dos subúrbios que se identificariam com a práti$\mathrm{ca}$, rompendo $\mathrm{cm}$ suas origens, circunscritas inicialmente a Zona Sul da cidade. Sua grafia nos jornais vai deixando de recorrer às aspas, ao destaque em itálico ou negrito, a ortografia inglesa do surf ou surfing para se tornar tão somente "surfe". E mesmo com a permanência de alguns estereótipos mais grosseiros - que também acabam incrementando a sua difusão - o surfe finalmente deixa de ser retratado como um hábito excêntrico, um modismo ou uma novidade extravagante $\mathrm{e}$ passa a ser visto como um esporte.

Ainda assim, tal como a maioria dos outros esportes na natureza, o surfe continuaria sendo "um esporte diferente". Sua estrutura organizacional convive até hoje com um forte sentido de ambivalência. Mesmo diante do aumento progressivo das premiações e da sua indiscutível institucionalização, preserva-se o sentido de que surfe "é muito mais do que um esporte". Meu argumento é que essa ambivalência é uma "estrutura-estruturante" e desde sempre esteve presente neste esporte. Vimos como desde a primeira metade dos anos 60 esboços de uma organização nesses termos já estavam assinaladas com a presença de carpinteiros que vendiam "madeirites" ou com eventos organizados por uma federação extraoficial que contavam com apoio do governo e patrocínio da Coca-Cola. A questão é que naquele momento as condições materiais para esse tipo de desenvolvimento ainda eram muito incipientes, sem mencionar o fato de que uma mentalidade empresarial ainda não estava absolutamente estabelecida entre empreendedores brasileiros, o mesmo podendo ser dito dos surfistas,

Movimento, Porto Alegre, v. 15, n. 04, p. 257-286, outubro/dezembro de 2009. 
evidentemente. Nesse sentido, ideias ligadas a profissionalização ainda eram ideias "fora do lugar". Mesmo assim, já se pode notar os rudimentos do que, nos anos seguintes, apenas ganharia um corpo mais bem delineado. Trata-se, nos termos sugeridos por Fedoca (1975, p. 38), da passagem de um "comércio dos bastidores" para um "comércio com perspectivas mais amplas", mas sempre um comércio.

Praticamente, desde que começou o surf no Brasil,
desenvolveu-se paralelamente a ele uma atividade
de como ganhar dinheiro com surf. Inicialmente es-
sa atividade baseou-se no comércio puro e simples
que originou a formação e o crescimento do mercado
surfístico. Esse comércio incluía e abrangia todas as
variações de transação que têm pintado a até pouco
tempo. A primeira atividade que pintou foi a venda
dos artigos principais para o surf, como calções, pa-
rafina, etc..., que era feita pela moçada que viajava e
trazia esses artigos e os vendia sempre em pequena
quantidade para uma rapaziada conhecida. Com o
tempo, esse "comércio dos bastidores" abriu pers-
pectivas tão amplas que originaram a abertura das
"surf shops", que atualmente só tem se multiplicado.

A própria visão de mundo dos surfistas, "preocupados em não se preocupar", favoreceu a marcha desse processo de comercialização com perspectivas mais amplas. Seus praticantes, a partir das referências de comportamento típicos a esta modalidade, instituídos nos termos próximos de uma communitas espontânea, tendiam a uma postura de "deixa pra lá", "tudo bem". Em última instância, esta característica garantiu as condições para que todos esses processos se instituíssem de forma mais rápida no surfe quando comparado a outros esportes na natureza, como o montanhismo por exemplo, cujo sistema de valores sempre mobilizou seus praticantes a uma postura militante frente às iniciativas de comercialização (DIAS, 2007).

Mas isto não significa que a força exercida pela comunidade ou pelas estruturas do esporte fossem menores, pois definitivamente não o eram. O surfe tem também seu código de condutas que emite seus juízos sobre a boa e a má maneira de se relacionar com o esporte. Nesse caso, as interdições não eram nem menores nem maiores, mas de naturezas diferentes. Talvez por isso vê-se no surfista um comportamento mais “desbundado", para usarmos uma expressão da época.

Movimento, Porto Alegre, v. 15, n. 04, p. 257-286, outubro/dezembro de 2009. 
Com a popularidade que alcançou nesses últimos
anos, o surf se tornou alvo da curiosidade de uma
imensa massa popular que compensa os investimen-
tos feitos no campo surfístico. A transmissão de cam-
peonatos através da televisão, as notícias de jornais
e revistas, se tornam uma imensa propaganda para
qualquer patrocinador desses campeonatos [...] Eu,
pessoalmente falando, acho que tudo isso vai trazer
um clima de competição dentro do surf (que aliás já
existe em grande escala no exterior), que vai ser bom
para o sistema todo, mas que atinge frontalmente a
minha filosofia e concepção de surf, onde ele faz
parte da vida como lance importante por si mesmo,
pela harmonia com a natureza. Como uma realidade
desligada de interesses financeiros e competições,
em que a disputa existe numa escala natural só como
uma motivação a mais para melhorar. Mas deixa pra
lá tudo isso, enquanto a rapaziada estiver em cima
das pranchas pegando as ondas por aí e arrepiando e
lei da gravidade, tudo bem, vamos nessa que é o boi
(FEDOCA, 1975).

Em suma, a presença de um mercado parece não ter inviabilizado, ao menos não completamente, a realização dos ideais da cultura surfe. Ao contrário, talvez tenha sido esse mercado que os tornou possíveis, levando os simbolismos do esporte até as casas das pessoas. Por tudo, é difícil pensar o surfe em termos dicotômicos, como sendo a expressão de um impulso libertário e contestador, por um lado, ou a manifestação de lógicas de lucro e mercantilização por outro. Não é possível abstrair o desenvolvimento do surfe do contexto social mais geral em que este se deu. O surfe e os surfistas são produtos de uma época marcada pela industrialização de várias esferas sociais, marcado, em suma, pelo momento em que a modernidade ou o capitalismo como um processo civilizatório deixa de ser um conjunto de aspirações e, finalmente, se realiza no domínio dos fatos - processo que Renato Ortiz (1994) chamou de "a moderna tradição brasileira". Seu impulso no Brasil coincide, portanto, com o surgimento de uma indústria da cultura. E é neste e por este quadro que o esporte se propaga.

Movimento, Porto Alegre, v. 15, n. 04, p. 257-286, outubro/dezembro de 2009. 


\begin{abstract}
The surf and the modern brazilian tradition
Abstract: In this work, it is intended to describe and to analyze the history of surf in Rio de Janeiro, in order to infer elements of more general reflection on the way of development of its structures of functioning. The idea is to explore the relations between this sport and the social circumstances more general than had followed to it and same they had produced to it, trying, in this way. With this purpose, the used sources had been periodical news articles and magazines of the time, such as O Globo, Jornal do Brasil, Jornal dos Sports, Veja, Fatos e Fotos, O Cruzeiro, Brasil Surf, beyond interviews with personages who had carried out part of the treat events here.

Keywords: Surf. Sports. Nature. History.
\end{abstract}

\begin{tabular}{|l|}
\hline El surf y la moderna tradicion brasileña \\
Resumen: En este trabajo, se pretende describir y ana- \\
lizar la historia del surf en Rio de Janeiro, a fin de mirar \\
los elementos de reflexión más general sobre la manera \\
de desarrollo de sus estructuras de funcionamiento. La \\
idea es explorar las relaciones entre este deporte y las \\
circunstancias sociales más generales que él acompañó \\
y incluso él produjeron intentando. Las fuentes utiliza- \\
das fueran los periodicos de la epoca, como O Globo, \\
Jornal do Brasil, Jornal dos Sports, Veja, Fatos e Fotos, \\
O Cruzeiro, Brasil Surf, asi como entrevistas con per- \\
sonas que participaran de los acontecimientos. \\
Palabras clave: Surf. Deportes. Naturaleza. Historia.
\end{tabular}

\title{
REFERÊNCIAS
}

ARIAS, Marcelo. Surf gênese. Alma Surf, São Paulo, n. 12, 2002.

OS ATLETAS da natureza. Veja, São Paulo, n. 700, p.54, 3 fev., 1982.

BOCÃO, Ricardo. O “quarto” boom. Fluir, São Paulo, jan., 2004.

BOTH, David. Ambiguities in pleasure and discipline: the development of competitive surfing. Journal of Sport History, v. 22, n. 3, 1995.

CAMPEONATO de Saquarema. Brasil Surf, Rio de Janeiro, v. 1, n. 1, p.28, mar./abr., 1975.

CASTRO, Ruy. Ela é carioca: enciclopédia de Ipanema. 3. ed. São Paulo: Companhia das Letras, 1999.

Movimento, Porto Alegre, v. 15, n. 04, p. 257-286, outubro/dezembro de 2009. 
COLASSANTI, A. Arduíno Colassanti: depoimento [jun. 2007]. Entrevistadores: Cleber Augusto Gonçalves Dias; Raquel Pinto Linhares. Rio de Janeiro: UFRJ/IFCS, 2007. Arquivo digital WAVE (49 minutos). Entrevista concedida a esta pesquisa.

DIAS, Cleber. Urbanidades da natureza: os esportes e a cidade do Rio de Janeiro. Dissertação (Mestrado em História Comparada) - Universidade Federal do Rio de Janeiro, Rio de Janeiro, 2007.

DIAS, Cleber; MELO, Victor; ALVES JÚNIOR, Edmundo. Os estudos dos esportes na natureza: desafios teóricos e conceitos. Revista Portuguesa de Ciências do Desporto, Lisboa, v. 7, n. 3, set./dez., 2007.

D'OREY, Fred. Desconstruindo Mickey Dora. Fluir, São Paulo, p.14, abr., 2006.

EDITORIAL. Brasil Surf, Rio de Janeiro, v. 1, n. 4, p.7, nov./dez., 1975a.

Brasil Surf, Rio de Janeiro, v. 1, n. 1, p.5, mar./abr., 1975b.

Brasil Surf, Rio de Janeiro, v. 1, n. 3, p.9, set./out., 1975 c.

FEDOCA: um futuro próximo. Brasil Surf, Rio de Janeiro, v. 1, n. 3, p.38, set./out., 1975.

FERNANDA, campeã carioca. O Globo, Rio de Janeiro, p.6, 27 set., 1965. Edição Esportiva.

FORD, Nick; BROWM, David. Surfing and social theory. New York: Routledge, 2006.

GERAÇÃO cocota. Veja, São Paulo, p.52-75, 4 jun., 1975.

GRANDE "ouverture" do verão 63. O Cruzeiro, Rio de Janeiro, p.24-32, 18 jan., 1964.

GUTENBERG, Alex. A história do surf no Brasil: 50 anos de aventura. São Paulo: Azul, 1989.

HOIBIAN, Olivier. De l'alpinisme à l'escalade libre: l'invention d'un style? Staps, Paris, v. 995, n. 36, 2005.

KAMPION, Drew; BROWN, Bruce. Stoked: a history of surf culture. Utah: Gibbs Smith, 2003.

KERR, Yllen. Campeonato de "surf" mostrou que americanos são os bons. Jornal do Brasil, Rio de Janeiro, p.18, 26 abr., 1966.

MARCUS, Ben. A história das pranchas de surf. Alma Surf, São Paulo, v. 7, n. 39, jul./ ago., 2007.

A NOVA ordem é de pé sôbre as ondas. O Cruzeiro, Rio de Janeiro, p.92, 18 jan., 1964.

ORTIZ, Renato. A moderna tradição brasileira: cultura brasileira e indústria cultural. 5. ed. São Paulo: Brasileinse, 1994.

Movimento, Porto Alegre, v. 15, n. 04, p. 257-286, outubro/dezembro de 2009. 
SAQUÁ sweet Saquá. Brasil Surf, Rio de Janeiro, v. 1, n. 4, p.36, nov./dez., 1975.

SAQUAREMA 76. Brasil Surf, Rio de Janeiro, v. 2, n. 1, p.19, jul./ago., 1976.

SAQUAREMA 77: deitando na fama. Brasil Surf, Rio de Janeiro, v. 2, n. 6, p.11, jul./ ago., 1977.

SHAUN Thomson. Brasil Surf, Rio de Janeiro, v. 1, n. 3, p.33, set./out., 1975.

SILVEIRA, Bento Xavier da. Editorial. Brasil Surf, Rio de Janeiro, v. 2, n. 6, p.7, jul./ago., 1977.

SOUZA, Rico de. A importância do piér de Ipanema. Jun., 2007. Disponível em: <http://www.blogdorico.globolog.com.br/archiv>. Acesso em: 14 agosto 2007.

SURF deu bicampeonato carioca a Fernanda. Jornal dos Sports, Rio de Janeiro, p.14, 28 nov., 1966.

SURF na véspera da decisão. Jornal do Brasil, Rio de Janeiro, p.1, 1 out., 1965. Caderno B.

SURFE: atletas da onda. Veja, São Paulo, p.91, 6 jul., 1977.

SURFE: em busca de apoio. Veja, São Paulo, p.61, 1 ago., 1973.

TOQUES. Brasil Surf, Rio de Janeiro, v. 1, n. 3, p.43, 1975.

UBATUBA. Brasil Surf, Rio de Janeiro, v. 1, n. 3, p.14, set./out., 1975.

VELHO, Gilberto. Nobres e anjos: um estudo de tóxicos e hierarquia. Rio de Janeiro: Fundação Getúlio Vargas, 1998.

YOUNG, Nat. The history of surfing. 2. ed. Utah: Gibbs Smith, 1994. 